\title{
Agricultural suitability assessment and rehabilitation of subsided coal mines: a case study of the Dawu coal mine in Jiangsu, Eastern China
}

\author{
Xiaomeng Yao and Xin Cui ${ }^{*}$ (i)
}

\begin{abstract}
Land-use suitability assessment crucial is for coal mine rehabilitation planning, especially for the coal mines that have undergone varying degrees of mining subsidence. In this study, we present an assessment on the suitability of crop cultivation in the Dawu coal mining district in NW Jiangsu province, Eastern China. Distribution of local land subsidence is delineated with topographic analysis, and the weight-of-evidence (WoE) suitability assessment has encompassed various factors including the conditions of soil (e.g., acidity and porosity), groundwater level, irrigation and drainage, terrain slope, and land pollution. Consequently, the Dawu district is divided into four categories (high, moderate, low, very-low) of agricultural suitability. Collaborating with the local government agencies (e.g., Land and Resources Bureau and Agriculture Bureau), a land-use plan is proposed. In the plan, the highly suitable areas for agriculture (and the surrounding moderately suitable areas) are allocated as farmlands, whilst the other moderately to lowly suitable areas are allocated as ecological zones for restoring the ecosystem and ecological diversity. The barely suitable areas with severe subsidence are allocated as artificial lakes, which also serve as reservoirs for farmland irrigation and drainage. To protect these new farmlands from soil erosion, infrastructure such as embankment and windbreak are also included in our rehabilitation plan. Our study highlights the necessity of forward planning in coal mine rehabilitation.
\end{abstract}

Keywords: Agricultural suitability assessment, Coal mining subsidence, Mine rehabilitation, Ecosystem restoration, Eastern China

\section{Introduction}

With China gradually switching to greener energy and technology, many coal mines have been shut down in recent years. Many of these closed mines are distributed in densely populated regions, notably in Eastern China, and the reuse (rehabilitation) of these lands has become a pressing issue (Bai et al. 2018; Dai and Finkelman 2018; Wang et al. 2020). The issue is further complicated by the fact that many of the closed coal mines have varying degrees of land subsidence, led by groundwater rise and

*Correspondence: xincui1@outlook.com

Geological Museum of China, Beijing, China collapse of abandoned underground mine workings ( $\mathrm{He}$ et al. 2008). Land subsidence could cause potential loss of lives and properties if infrastructures (e.g., residential buildings, bridges, roads and railways) are built on sites that are subsided or with a high potential of future subsidence, and the cost of the subsequent land remediation can be substantial. Therefore, careful planning is needed to ensure sensible/sustainable land-use and to restore the environment and ecology of the region, as well as to revitalize regional economy (Szczepanska and Twardowska 1999; Zhang and Sun 2005; Dumanski et al. 2006).

Northwestern Jiangsu province in Eastern China is a historic coal mining region, and contains a number of 
large coalfields (Fig. 1). Previous studies on closed mine rehabilitation were mainly dedicated to that in large cities (e.g., Xuzhou) and their impact on urban areas. In contrast, rehabilitation research on rural areas, especially on restoring the subsided areas for crop cultivation, is scarce. It is well known that underground coal mining and the related subsidence has profound impact on agricultural productivity, through altering the local topography, soil properties, and underground hydrology (Fig. 2) (Lechner et al. 2016). In this study, therefore, we selected the Dawu mining district in the Xuzhou coalfield for a case study. Based on analysis of the local topography, we mapped out the sites of mining subsidence. We formulated the factors and Weight of Evidence (WoE) to evaluate the agricultural suitability for crop cultivation. Our evaluation results divide the study area into four categories of suitability (i.e., high, moderate, low, very-low) for cultivation. According to the agricultural suitability and local topography, we devised a land-use plan for the district, comprising lands for cultivation and for ecological restoration, e.g., parks, forests, and artificial lakes. Details for the design of embankment, land levelling, windbreak, together with agricultural irrigation and drainage are also introduced as part of the plan.

\section{Dawu coal-mining district and land subsidence}

The Dawu district is located $35 \mathrm{~km}$ NE from Xuzhou city (latitude: $34^{\circ} 17^{\prime} \sim 34^{\circ} 32$ ', longitude: $117^{\circ} 17^{\prime} \sim 117^{\circ} 42^{\prime}$, size: $11,259 \mathrm{~km}^{2}$ ) in the southeastern North China Plain (aka. Huang-Huai-Hai Alluvial Plain) (Fig. 1a). At 2016, the land use of Xuzhou consists mainly of farmland (5989.33 $\left.\mathrm{km}^{2}\right)$ and built-up area $\left(2434 \mathrm{~km}^{2}\right)$, followed by recreation $\left(556.67 \mathrm{~km}^{2}\right)$, forest $\left(248 \mathrm{~km}^{2}\right)$, coal mining $(97.33$ $\left.\mathrm{km}^{2}\right)$, and grassland $\left(61.33 \mathrm{~km}^{2}\right)$. Water bodies made up of $1739.67 \mathrm{~km}^{2}(15 \%)$ of the city area (Fang et al. 2019 and ref. therein). The district is an important component of the Xuzhou coalfield, encompassing many counties and townships, including the Dawu, Dongdawu, Rencangwu, Duiwei, and Duiweizi (Fig. 1b, c). The primary coalbearing sequences are the Upper Carboniferous Taiyuan Formation and the Lower Permian Shanxi and Lower Shihezi formations, which may have mainly deposited in large epicontinental sea basins (Li 2012; An et al. 2018; Li et al. 2018; Zheng et al. 2019). The Permian coal seams are economically more important, because they are thicker and more continuous. The Shanxi Formation may have deposited in a tidal-flat delta with brackish water influence, whilst the Shihezi Formation likely deposited in a delta plain with occasional seawater incursion (Li et al. 2020 and ref. therein). Sandwiched between the waterbodies of the Pan'anhu National Wetland Park
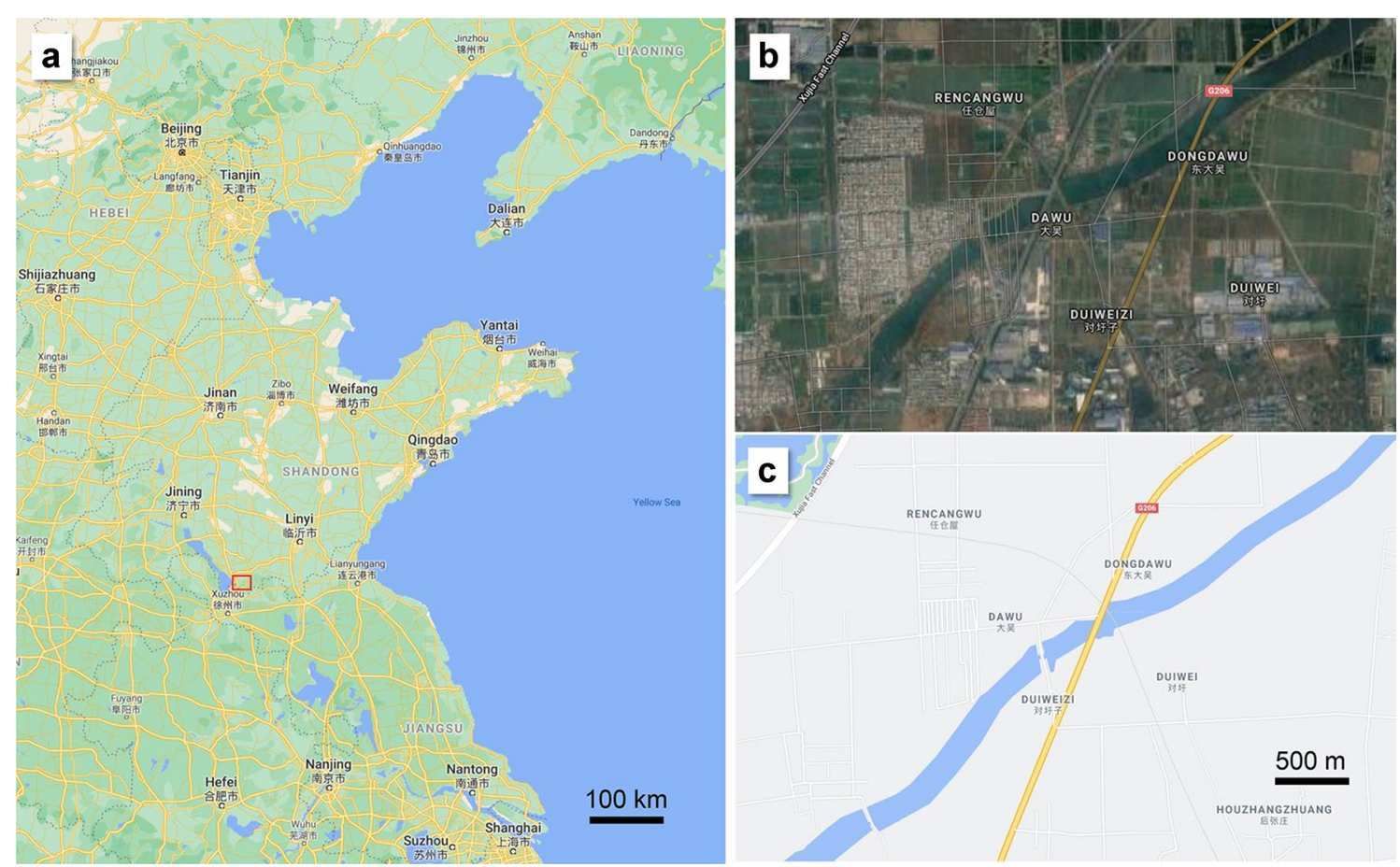

Fig. 1 a Map of Eastern China, showing the location of the study area (in red rectangle); b Satellite image and $\mathbf{c}$ map of the Dawu mining district. All satellite image and maps from Google Map 


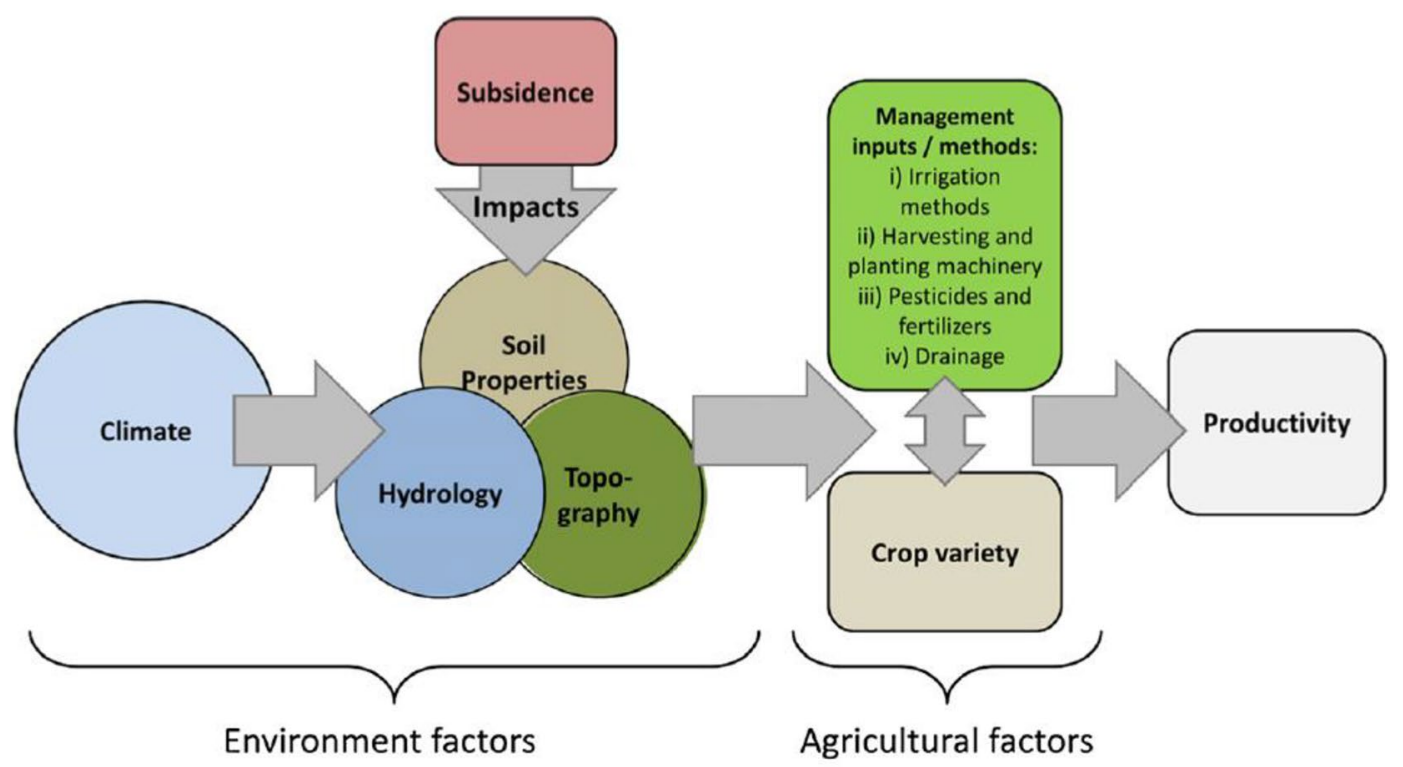

Fig. 2 Schematic diagram showing the impacts of coal mining subsidence on agricultural productivity (Lechner et al. 2016)

and the Bulao river, the Dawu district is topographically flat and encompasses an area of $38.28 \mathrm{~km}^{2}$. After the mine closure, it is estimated that almost one-third of the district $\left(10.50 \mathrm{~km}^{2}\right)$ has varying degrees of the mining subsidence, and the subsidence extends across the middle-southern parts of the district. The subsided area includes $8.97 \mathrm{~km}^{2}$ agricultural land, $1.06 \mathrm{~km}^{2}$ construction land, and $0.47 \mathrm{~km}^{2}$ unused land. The spatial distribution of these subsided areas in the district is delineated here and shown in Fig. 3.

\section{Agricultural suitability evaluation for the Dawu mining district}

\section{Evaluation units and factors}

In this study, the land-use map and topographic images (including aerial photos and satellite images) are used as units for the agricultural suitability evaluation. A wide range of internal/external conditions were considered as the evaluation factors, including the soil condition (e.g., acidity and porosity) (Parikh and James 2012), groundwater level (Siebert et al. 2010; Ho et al. 2016), irrigation and drainage conditions (van der Zee et al. 2017), slope of terrain (Turunen et al. 2015), land pollution condition (e.g., heavy metal and arsenic contents; Dai et al. 2012; Zhao et al. 2018), and the past and current land use status (Bhattacharya 2011). In this study, we have merged these into seven major factors (Table 1): Land pollution condition is crucial for agricultural suitability evaluation, and is thus given the highest weight (0.234). At Xuzhou, although the mean concentrations of $\mathrm{Cr}(70.266 \mathrm{ppm}), \mathrm{Hg}$ (0.036 ppm), and $\mathrm{Pb}(24.84 \mathrm{ppm})$ exceed their respective background values, they are still below the Chinese environmental quality standard for soils (GB15618-1995) (Fang et al. 2019). These harmful substances (arsenic, selenium, and heavy metals) may have been products of acid mine drainage, for instance from the weathering of pyrite in the coal (Huang et al. 2009; An et al. 2018). Besides, in the Jiawang district of Xuzhou, where most of the coal mining activities are/were located (including the Dawu mine), the ecological risk imposed by heavy metal contamination was estimated to be moderate (Fang et al. 2019). Therefore, the weight for land pollution condition is the highest but not dominating. The second most important factor is the soil conditions (0.192), which include the soil type and $\mathrm{pH}$ (Mchinga et al. 2005). At Xuzhou, the soil type is mainly alluvial, and the soil acidity is contributed by a combination of acid rain and acid mine drainage (Han 1995), which both occur uniformly across Dawu. Irrigation and drainage conditions rank the third in terms of weight (0.171). At Dawu, irrigation is not a big issue because of the many water bodies nearby (notably the Bulao river), whilst drainage is usually better in areas with previous underground mining work. Both groundwater level (0.168) and terrain slope (0.113) have moderate to low weight, because they do not vary much across the study area: groundwater level is generally high at Dawu because of the many water bodies nearby, and the terrain is largely flat apart from the subsided sites. Original land use is of minor unimportance (weight $=0.071$ ), because most of the study area was a coal mine, except for the places, where roads or power lines are built. Most external factors (e.g., climate, 

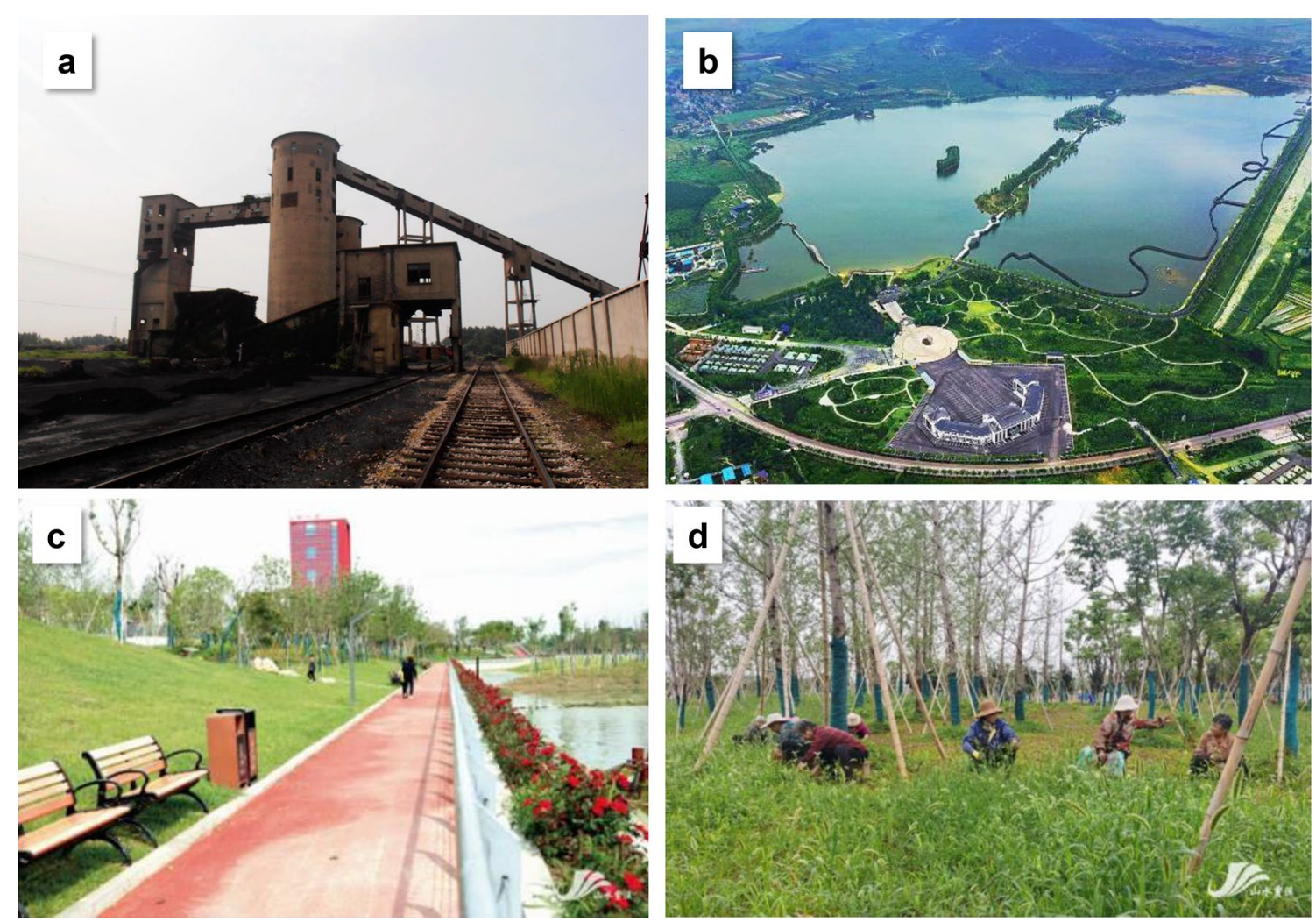

Fig. 3 Photos of a coal mine in operation (photo taken in the 1990s) and b coal mine after rehabilitation with ecological parks and artificial lakes, Dawu mining district; $\mathbf{c}$, d ecological restoration zone (photos from http://js.people.com.cn/): c embankment along artificial lake, and $\mathbf{d}$ reforestation in the planned forest reserve

labor, market) are homogenous across the study area, with the exception of transportation facilities, which the sites closer to roads/railway stations would yield a slightly higher score (Fig. 4).

\section{Weight of Evidence (WoE) determination}

In this study, the results of the agricultural suitability analysis fall into four categories: Highly suitable (100 points), moderately suitable (80 points), lowly suitable (60 points), and barely suitable/unsuitable (0 point). The Delphi method is used to quantify the grading and weight of each factor (Linstone and Turoff 1975). An expert team is employed to build the analytical hierarchy, to establish the judgment matrix, and to conduct the consistency test. This expert team is mainly composed of professionals (e.g., engineers) from the Land and Resources Bureau, Agriculture Bureau, and Water Conservation Bureau of the Dawu district, together with researchers from the China University of Geosciences (Beijing), which have all been long involved (and thus well-experienced) in the land rehabilitation/remediation of the local mining subsidence. The data (e.g., heavy metal contents, soil type, and groundwater level) used for the assessment were largely compiled from unpublished internal government surveys and reports (in Chinese), dated back to the 1970s. Topographic evolution (incl. terrain slope) of the area was recognized through comparing aerial photos and topographic maps of different ages. These data and information were first digitized, and then analyzed and visualized using the ArcGIS software. The WoE factors and their relative weight for this assessment are shown in Table 1 . The index quantification rating, weight determination, and data processing is performed with the MAPGIS6.7 software, and the weighted sum method is used to calculate the total score of the attributes for each evaluation unit (Marler and Arora 2010).

\section{Evaluation results}

As shown in Fig. 5, the most-suitable land for cultivation is distributed in the northern and (mainly) northeastern parts of the study area, which commonly have minimal or no subsidence. The moderately suitable land extends east-west across the middle part of the orefield, whilst the lowly suitable land is distributed in the southeastern corner of the study area, as well as scattered within the moderately suitable land. The barely suitable or 


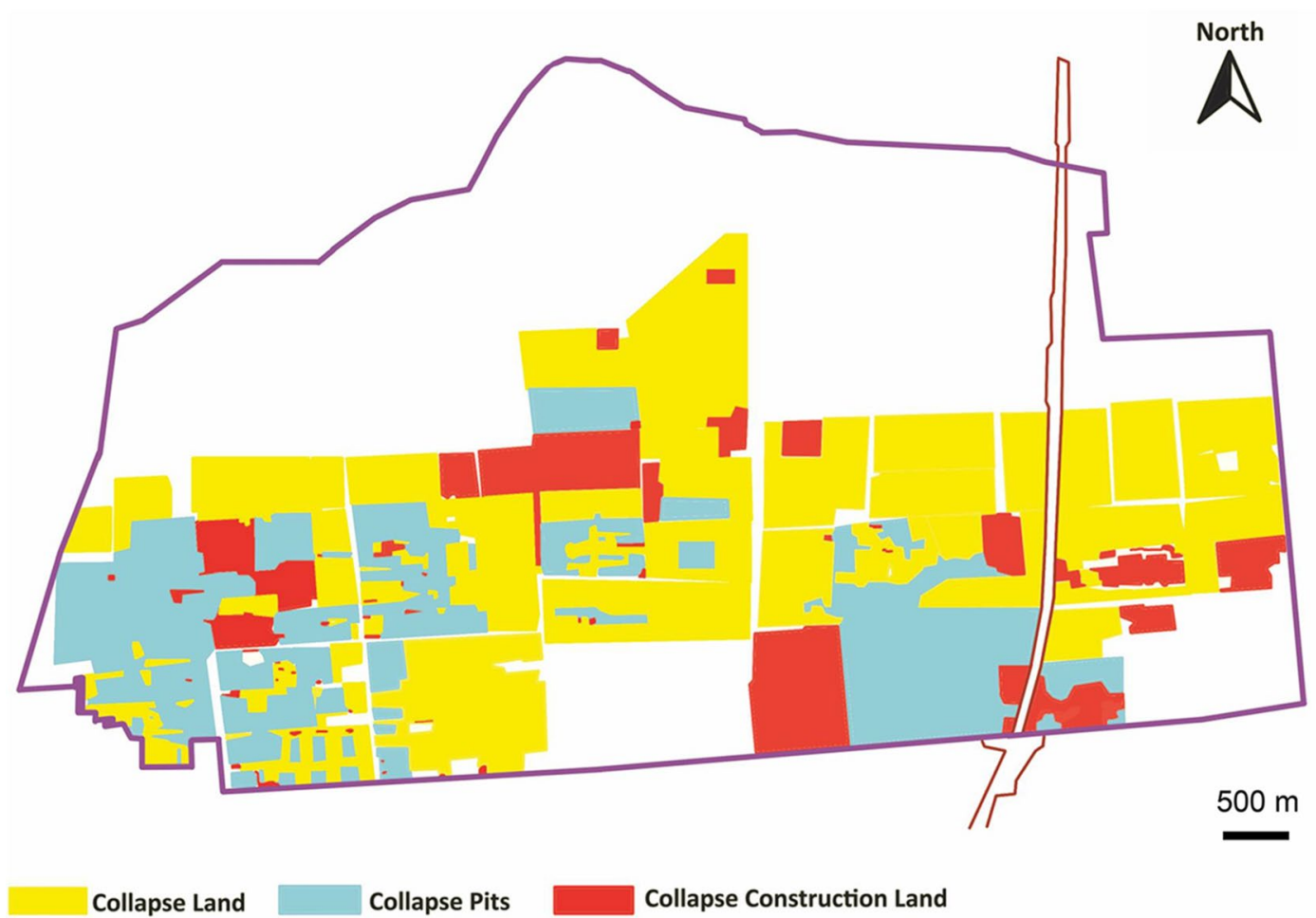

Fig. 4 Map showing the distributions of subsided pits (greyish-blue), subsided agriculture/unused land (yellow), and subsided construction land (red) in the Dawu mining district, Jiangsu province

Table 1 Weight of Evidence (WoE) for agricultural suitability assessment in the Dawu mining district, Jiangsu province

\begin{tabular}{ll}
\hline Evaluation factor & Weights \\
\hline Land pollution & 0.234 \\
Soil conditions & 0.192 \\
Irrigation and drainage conditions & 0.171 \\
Groundwater level & 0.168 \\
Terrain slope & 0.113 \\
Original land use & 0.071 \\
External condition & 0.005 \\
\hline
\end{tabular}

unsuitable land is mainly distributed in the southwestern corner, in the center, and along the southern fringe of the area, where land subsidence is generally severe.

\section{Rehabilitation land-use design in the Dawu mining district and future work}

Rehabilitation in the Dawu mining district has the following aims: (1) re-introduce agricultural activities to improve the local economy; (2) improve the living environment and standard for local residents; and (3) restore the ecological environment and diversity. Accordingly, our design is dedicated to meet these three aims. Reintroduction of agricultural land to Dawu is of particular importance, because since 1987, 9.55\% of the farmland in Xuzhou was lost to construction land, and a further $5.15 \%$ was lost because of waterlogging caused by land subsidence (Bian and Zhang 2006). Turning some of the subsided land into water bodies (as artificial lakes in recreation parks) improves not only the living environment of local population, but also the capacity of irrigation and flood prevention in the district.

\section{Rehabilitation plan for the Dawu district}

According to the afore-mentioned agricultural suitability and factors such as topography (caused by the varying degrees of subsidence), population distribution, and existing infrastructure (e.g., roads and bridges), a rehabilitation plan for the Dawu mining district is proposed (Fig. 6). All the most-suitable areas for cultivation in northern and southern Dawu, as well as some moderately suitable (and less-subsided or un-subsided) areas in eastern and western Dawu (Fig. 5) are allocated to agricultural area in the plan. The least-suitable or unsuitable areas in the southwestern corner and central-eastern part of the study area (originally a collapsed pit) are designed to be an artificial lake, which can also serve as both water 


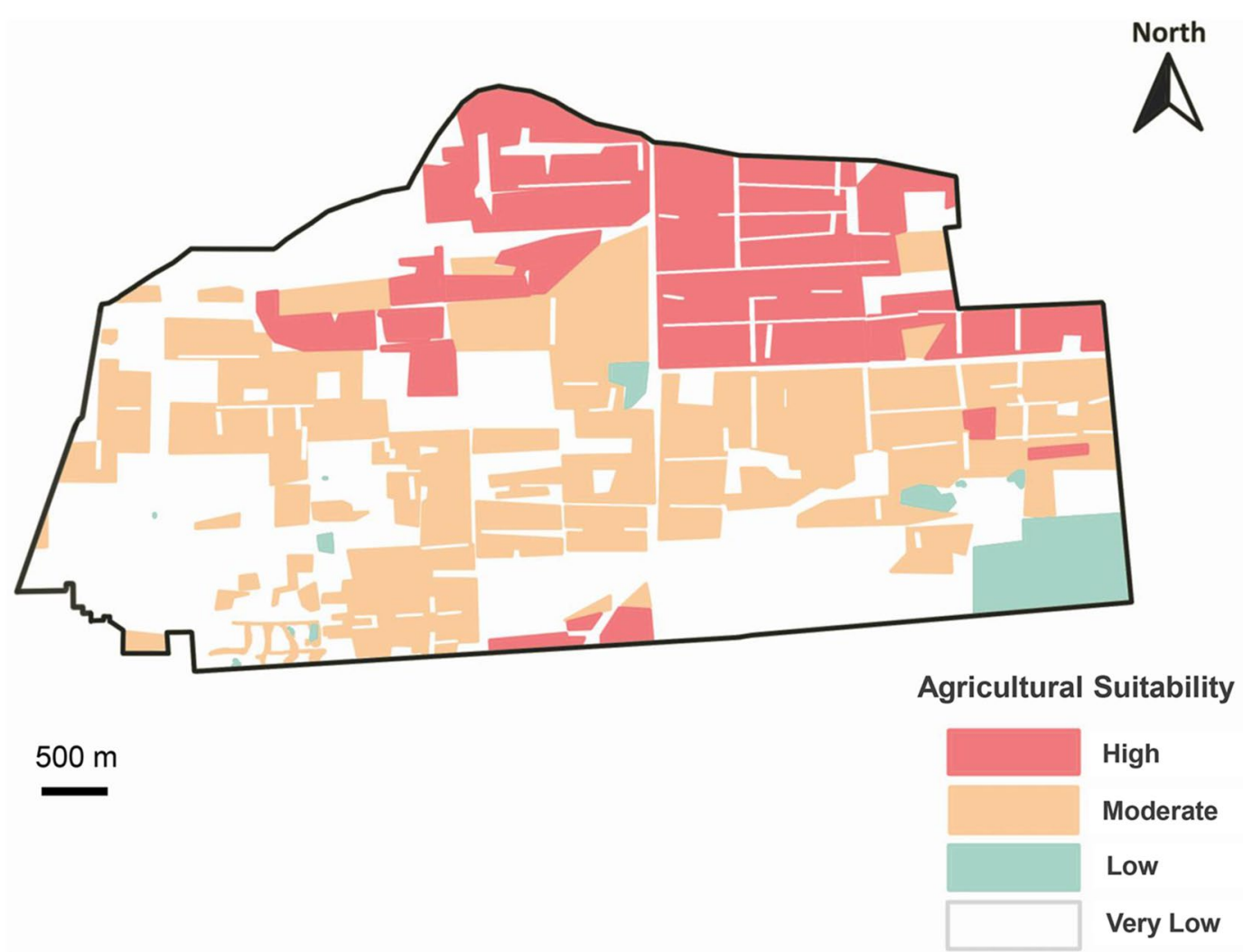

Fig. 5 Map showing the distributions of lands, where the suitability of rehabilitation is high (red), moderate (orange), low (green), and very low (white)

source for irrigating the nearby farmland and as a storage for runoff stormwater (to prevent flooding). The rest of the moderately suitable areas are allocated to the ecological zone, which consists mainly of parks plus three patches of forest reserves, where extensive greening will be carried out (Fig. 2d). To conserve these new farmlands from flooding or soil erosion (by wind), the following infrastructures are also added to the plan:

\section{Embankment design}

In the Dawu mining district, the areas suitable for cultivation are mostly low-lying (ca. 27.0-29.0 m elevation) and below the flood level of local waterbodies $(\sim 30.0 \mathrm{~m}$ elevation). To prevent flooding in the proposed farmlands, embankment is designed along the border of the cultivated land plots (Fig. 2c). To ensure that flooding would not occur even under severe raining during monsoon seasons, the width of the embankment is set to be $6 \mathrm{~m}$ ( $2 \mathrm{~m}$ wide at the top of the clay embankment wall), and the slope coefficient is set to be 1.5 , in line with the Chinese national standard. The water diversion and the bottom are protected by M10 pulp.

\section{Land leveling design}

1. Topsoil stripping backfill: To backfill the subsided areas, the tillage layer is set to be $18 \mathrm{~cm}$, whilst the thickness of the stripped topsoil is set to be $20 \mathrm{~cm}$.

2. (2) Landform earthwork calculation and topsoil reconstruction: Earthwork calculation is conducted with the grid method with the CASS software, with the basic calculation unit being the flattening unit (Liu et al. 2021). The topsoil reconstruction design consists of three parts: (1) Filling materials comprise fly ash, coal gangue, and lake mud, with their actual amount dependent on the local land configuration (e.g., degrees of land subsidence); (2) A $5 \mathrm{~cm}$ clay layer is placed on top of the fly-ash filling layer as an isolation, which is in turn covered with topsoil; (3) The required topsoil thickness is estimated to be $50 \mathrm{~cm}$. This estimation is based on the main types of crops (e.g., wheat, corn, and soybean) suitable for growth in the Eastern China region, and the local drainage conditions in Dawu. 


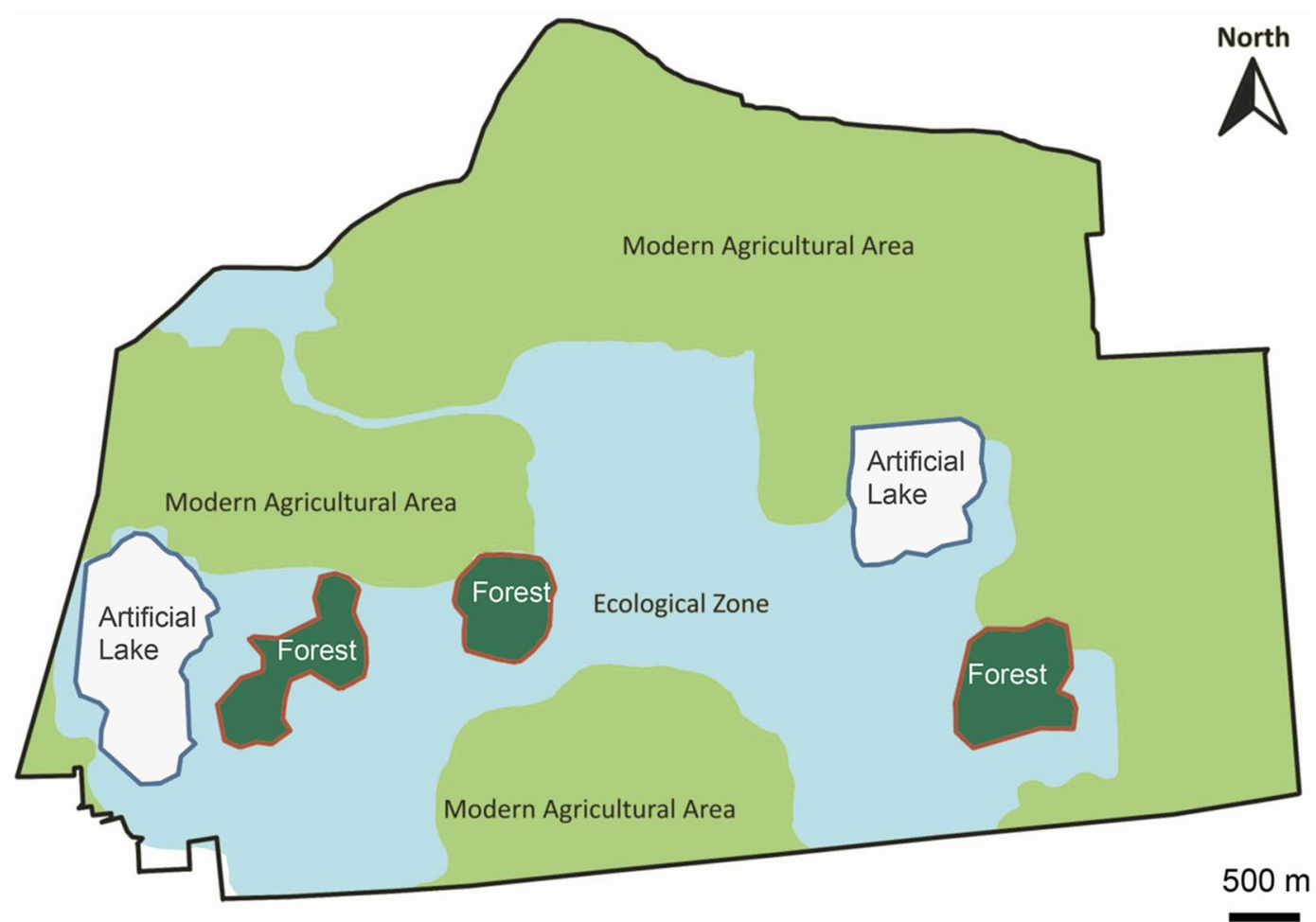

Fig. 6 Map showing the final plan for rehabilitation of the Dawu mining district, with different parts of the area allocated to artificial lake, forest, ecological (e.g., parks) and agricultural zones

\section{Windbreak design}

Although severe hurricanes or windstorms are uncommon in Dawu, strong wind can still cause surface soil ero-

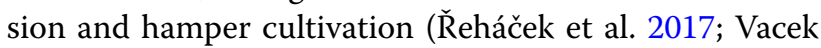
et al. 2018). As a result, windbreak is planned on both sides of the main roads in Dawu. The plants selected for the windbreak include mainly sophora japonica and willow $(n=24,232)$ and privet $(n=23,554)$, planted with spacing of $2 \mathrm{~m} \times 2 \mathrm{~m}$.

\section{Irrigation and drainage design}

Based on the irrigation requirements, new irrigation pumping stations are planned to raise water from local waterbodies (including the two artificial lakes and the Bulao river), and two-stage irrigation pipelines are designed with pipeline water utilization factor of 0.92 . Two types of corrosion-resistant water pipes are to be used for the farmland irrigation and drainage: Concrete pipes $(600 \mathrm{~mm}, 500 \mathrm{~mm}, 400 \mathrm{~mm}$, and $300 \mathrm{~mm}$ ) and PVC pipes $(250 \mathrm{~mm}, 200 \mathrm{~mm}, 160 \mathrm{~mm}, 110 \mathrm{~mm})$.

\section{Future work}

It is hugely important to conduct follow-up study on comparing the agricultural suitability between different cultivation crops, because many assessment factors (for instance local soil conditions (esp. $\mathrm{pH}$ ) and groundwater level) would have varying impacts on different crops. At Xuzhou, the major cultivation crops include rice, wheat, corn, and sweet potato. As the land rehabilitation is still underway, it is unclear which of these $\operatorname{crop}(\mathrm{s})$ is/are to be grown. We thus recommend that once the agricultural activities have commenced, follow-up studies should be conducted to examine which crop(s) is/are more suitable on these previous mining sites, as well as the extent of harmful (e.g., arsenic and heavy metals) substance uptake in these crops. This will be beneficial for future agricultural suitability assessment for similar historic coal mining districts in eastern/northern China.

\section{Conclusions}

In this study, we have put forward the first assessment on the agricultural suitability of coal mining subsidence lands in NW Jiangsu province, Eastern China. Delineation of subsided areas in the district was performed with topographic analysis. Weight-of-Evidence is assigned on the various internal and external influencing factors on crop cultivation. According to the assessment results, the most-suitable areas are allocated to agricultural lands, whereas the least-suitable and unsuitable (commonly also 
the most subsided) areas are allocated to artificial lakes and ecological restoration zone. The moderately-suitable areas can be allocated to either cultivation or ecological restoration, dependent on their size, topography, and proximity to the nearby farmland. Details of the infrastructures for conserving the farmland (e.g., preventing flooding or soil erosion) are also formulated, including the design for lake/river embankment, land levelling and topsoil replacement, windbreak construction, as well as measures for irrigation and drainage.

\section{Acknowledgements}

The study was part of the first author's MSc study under the supervision of the second author, supported by the China University of Geosciences (Beijing). We would like to thank the engineers and geologists in the expert team at Dawu for helping with the field investigation, suitability assessment, and the fruitful discussion on the rehabilitation design. The Editor-in-Chief Prof. Kenji Satake, the handling editor Prof. Yiping Wu, and two anonymous reviewers are thanked for their constructive reviews and comments.

\section{Authors' contributions}

$\mathrm{XY}$ acquired, analyzed, interpreted the data and wrote the manuscript, $\mathrm{XC}$ designed the work, supervised the project, and revised and edited the manuscript. Both authors read and approved the final manuscript.

\section{Funding}

The study was part of the first author's MSc study under the supervision of the second author, supported by the China University of Geosciences (Beijing). This study was funded by "Geological Museum of China".

\section{Availability of data and materials}

The data sets used and/or analyzed during the current study are available from the corresponding author on reasonable request.

\section{Declarations}

\section{Competing interests}

The authors declare that they have no competing interests.

Received: 11 May 2021 Accepted: 3 September 2021

Published online: 15 September 2021

\section{References}

An Y, Liu L, Wang M et al (2018) Source and enrichment of toxic elements in coal seams around mafic intrusions: constraints from pyrites in the Yuandian Coal Mine in Anhui, Eastern China. Minerals. https://doi.org/10. 3390/min8040164

Bai X, Ding H, Lian J et al (2018) Coal production in China: past, present, and future projections. Int Geol Rev 60:535-547. https://doi.org/10.1080/ 00206814.2017 .1301226

Bhattacharya SS (2011) Proposed criteria for assessing subsidence damage to renewable resource lands. Min Eng 14:204-206

Bian ZF, Zhang YP (2006) Land use changes in Xuzhou coal mining area. Acta Geogr Sin 61:349-358

Dai S, Finkelman RB (2018) Coal geology in China: an overview. Int Geol Rev 60:531-534. https://doi.org/10.1080/00206814.2017.1405287

Dai S, Ren D, Chou C-L et al (2012) Geochemistry of trace elements in Chinese coals: a review of abundances, genetic types, impacts on human health, and industrial utilization. Int J Coal Geol. 94:3-21. https://doi.org/10 1016/j.coal.2011.02.003

Dumanski J, Bindraban PS, Pettapiece WW, et al (2006) Land classifications, sustainable land management, and ecosystem health. Agric Sci Vol II - L Classif Sustain L Manag Ecosyst Heal 1-9

Fang A, Dong J, An Y (2019) Distribution characteristics and pollution assessment of soil heavy metals under different land-use types in Xuzhou City China. Sustain. https://doi.org/10.3390/su11071832
Han BP (1995) Interaction between the urban ecosystem and environment in Xuhou city. J Eng Geol 3:86-92 (in Chinese with English abstract)

He SJ, Guo HC, Wei CY, Liu W (2008) Land restoration in coal mining fields in China. Acta Geogr Sin 28:172-175

Ho M, Parthasarathy V, Etienne E et al (2016) America's water: Agricultural water demands and the response of groundwater. Geophys Res Lett 43:7546-7555. https://doi.org/10.1002/2016GL069797

Huang S, Hua M, Feng J et al (2009) Assessment of selenium pollution in agricultural soils in the Xuzhou District, Northwest Jiangsu, China. J Environ Sci (china) 21:481-487. https://doi.org/10.1016/S1001-0742(08)62295-0

Lechner A, Baumgartl T, Matthew P, Glenn V (2016) The impact of underground longwall mining on prime agricultural land: a review and research agenda. L Degrad Dev 27:1650-1663. https://doi.org/10.1002/ldr.2303

Li P (2012) Study on Regularity and Prediction Method of Surface Subsidence Due to Deep Mining - Taking Xuzhou Coal Mining Area as Example. China University of Mining and Technology. PhD thesis

Li Z, Wang D, Lv D et al (2018) The geologic settings of Chinese coal deposits. Int Geol Rev 60:548-578. https://doi.org/10.1080/00206814.2017.1324327

Li Y, Huang W, Jiu B et al (2020) Modes of Occurrence and Origin of Minerals in Permian Coals from the Huainan Coalfield, Anhui, China. Miner. 10:1

Linstone HA, Turoff M (1975) The Delphi Method: Techniques and Applications. Addison-Wesley Pub. Co., Advanced Book Program

Liu Q, Duan Q, Zhao P et al (2021) Summary of calculation methods of engineering earthwork. J Phys Conf Ser 1802:32002. https://doi.org/10.1088/ 1742-6596/1802/3/032002

Marler R, Arora J (2010) The weighted sum method for multi-objective optimization: new insights. Struct Multidiscip Optim 41:853-862. https://doi. org/10.1007/s00158-009-0460-7

Mchinga JC, Van Ranst E, Baert G (2005) Land suitability assessment for sugarcane cultivation in "Herois de Caxito" (Angola). Tropicultura 23:77-84

Parikh SJ, James BR (2012) Soil: the foundation of agriculture. Nat Educ Knowl $3: 2$

Řeháček D, Khel T, Kučera J et al (2017) Effect of windbreaks on wind speed reduction and soil protection against wind erosion. Soil Water Res. 12:128-135. https://doi.org/10.17221/45/2016-SWR

Siebert S, Burke J, Faures JM et al (2010) Groundwater use for irrigation - A global inventory. Hydrol Earth Syst Sci 14:1863-1880. https://doi.org/10. 5194/hess-14-1863-2010

Szczepanska J, Twardowska I (1999) Distribution and environmental impact of coal-mining wastes in Upper Silesia, Poland. Environ Geol 38:249-258. https://doi.org/10.1007/s002540050422

Turunen M, Warsta L, Paasonen-Kivekäs M et al (2015) Effects of terrain slope on long-term and seasonal water balances in clayey, subsurface drained agricultural fields in high latitude conditions. Agric Water Manag. 150:139-151. https://doi.org/10.1016/j.agwat.2014.12.008

Vacek Z, Řeháček D, Cukor J et al (2018) Windbreak efficiency in agricultural landscape of the central europe: multiple approaches to wind erosion control. Environ Manage 62:942-954. https://doi.org/10.1007/ s00267-018-1090-x

van der Zee S, Stofberg S, Yang X, et al (2017) Irrigation and Drainage in Agriculture: A Salinity and Environmental Perspective. In: Current Perspective on Irrigation and Drainage. pp 1-21

Wang X, Tang Y, Wang S, Schobert HH (2020) Clean coal geology in China: research advance and its future. Int J Coal Sci Technol 7:299-310. https:// doi.org/10.1007/s40789-020-00321-4

Zhang JF, Sun QX (2005) Causes of wetland degradation and ecological restoration in the Yellow River Delta Region. For Stud China 2:77-78

Zhao Y, Yang J, Ma S et al (2018) Emission controls of mercury and other trace elements during coal combustion in China: a review. Int Geol Rev 60:638-670. https://doi.org/10.1080/00206814.2017.1362671

Zheng M, Zhang H, Deng Ket al (2019) Analysis of pre- and post-mine closure surface deformations in western Xuzhou coalfield from 2006 to 2018. IEEE Access. https://doi.org/10.1109/ACCESS.2019.2938846

\section{Publisher's Note}

Springer Nature remains neutral with regard to jurisdictional claims in published maps and institutional affiliations. 